International Journal of Linguistics, Literature and Translation

ISSN: 2617-0299 (Online); ISSN: 2708-0099 (Print)

DOI: 10.32996/ijltt

Journal Homepage: www.al-kindipublisher.com/index.php/ijltt

\title{
Graded Readers: An Empirical Study Measuring the Impact on Low-Proficiency EFL Students' Writing Fluency in Morocco
}

\author{
Prof. El Morabit Nadir 8 (D) \\ EFL Teacher, Al Imam Al Ghazali High school, Tetouan, Morocco \\ $\triangle$ Corresponding Author: Prof. El Morabit Nadir, E-mail: ndrmorabet@gmail.com
}

\author{
ARTICLE INFORMATION \\ Received: May 11, 2021 \\ Accepted: June 22, 2021 \\ Volume: 4 \\ Issue: 6 \\ DOI: $10.32996 /$ ijllt.2021.4.6.28
}

\section{KEYWORDS}

Graded readers, curricular

alternatives, curricular intervention, instructional content, optimal

engagement

\section{ABSTRACT}

The writing ability of Moroccan students is generally characterized by low language fluency. This article examines the impact of the implementation of graded readers as a syllabus intervention alternative rather than the textbook-based approach regarding teaching writing skill. The research design for this study is a mixed method. The qualitative method was twofold, in-class and online. The first tool was conducted via a series of observations and structured discussions with students. Likewise, the second tool was conducted through online forum interactions between the students one another and students with their instructor so as to measure their perceptions on the use of graded readers as a new method of dealing with the writing skill in preparation for the formative assessment quiz. Microsoft Teams platform, commissioned by the Ministry of Education, was used as a complementary medium to enhance in-class discussions where students are required to answer some open-ended questions. On the other hand, the quantitative method was used to measure the students' outcomes by using the Rubric Calculator Software issued by Smekenseducation.com. The findings of this study demonstrate that the use of graded readers to improve the writing fluency was encouraging according to the positive results obtained from the analyzed data regardless of the time restrictions. The paper is concluded with several recommendations for more research in the field of study and the requirements needed for the best implementation of this creative method to boost the learners' writing fluency.

\section{Introduction}

In the past few decades, the focus on graded readers instead of the reading skill per se started to emerge stepwise. The persistent reason behind this shift is the role these levelled series of readings can play on the proficiency level of EFL students. Unfortunately, the Moroccan English syllabus is heavily textbook-based which makes it difficult for Moroccan teachers to make major "curricular interventions" to cater for students' learning needs (Johnson, 2014, p. 199). As a teacher of EFL students, the principal hindrance for students' career advancement in learning English is the writing skill. This raises several timely issues related to the motivational engagement of students who tend to see themselves as low achievers in the writing skill. In this article, I argue that graded readers are a source of "a strong content basis for students to base a discussion on" (Cooper, 2020, p.23). This discussion should be conducive to how these graded readers can be a provision of input or what Krashen call "comprehensible input" (Krashen,1993, p.37) to the learners with "limited linguistic knowledge" (Day \& Bamford, 1998) to write fluently rather than accurately since the focus is to encourage low-proficiency students to write a paragraph with lexical coverage reflecting the implicit acquisition of vocabulary and grammatical structures to produce a paragraph rather than measuring the accuracy of the learners outcomes. To achieve this, a mixed-method study will be used to measure my students' perceptions as a dependent variable quantitatively via in-class and online discussion boards, and quantitatively measuring the writing fluency by grading the students' outcomes using The Rubric Calculator Software developed by Smekenseducation.com. This rubric was limited in quantifying the percentages, but it was customized to serve the purpose of the study. The paper is concluded with

\section{K C AL-KINDI CENTER R D FOR RESEARCH AND DEVELOPMENT}

Your gateway to world-class research

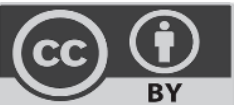

Published by Al-Kindi Center for Research and Development, London, United Kingdom. Copyright (c) the author(s). This open access article is distributed under a Creative Commons Attribution (CC-BY) 4.0 license 
practical recommendations for the stakeholders and teachers regarding the materials supplied and the current teaching practices in how writing is approached.

\section{Literature Review}

Little inquiry has been directed towards the impact of graded readers on students' writing. Here we examine prior work and go on to propose our own methods for an effective implementation of greater retention of vocabulary and certain standards of writing judgments. There have been multiple previous attempts to investigate the impact of graded readers on the students' writing fluency.

In his outstanding book The Power of Reading: Insights from the Research, Krashen advocates that "writing style does not come from actual writing experience, but from reading" (Krashen, 1993, p.132). He argues that researchers have not yet managed to map what a good writing style is. Accordingly, he concludes that the previous works did not come up with a concrete evidence to highlight the linkage between writing and the writing style, which he believes it is absorbed rather than learned ( $p .133$ ). In his attempt to explore the issue of writing fluency, Smith maintained that: "I thought the answer [to how we learn to write] must be that we learn to write by writing until I reflected on how little anyone writes in school, even the eager students, and how little feedback is provided.... No one writes enough to learn more than a small part of what writers need to know" (Smith, 1988, as cited in Krashen, 1993). Subsequently, Smith concludes that the process of writing should be reiterative so that students can write well. Likewise, this advocacy was reinforced by other studies like those of Applebee, Langer, and Mullis (1986) and Rice (1986) who advocates for the reading and writing liaison hypothesis, but the results were not satisfactory and yet the demarcation between the writing quantity and quality persists. Having reviewed different reports and works between the 1960 s and 2000s, Krashen (1993) reached a strong conviction that language acquisition comes from input not output. As far as Krashen concerned, "no studies, to my knowledge, have attempted to find a relationship between what is read and writing style" (p.136). It becomes clear from the previous works that writing fluency is still debatable and open for discussion whether it is a matter of writing frequency, or an incidental acquisition process.

\subsection{Definition of graded readers}

According to Cambridge Dictionary (n.d.), graded readers are series of books of increasing levels of difficulty, used for teaching people to read, or to help them learn a foreign language by reading (Cambridge Dictionary, n.d.). Moreover, the Erfoundation refers to graded readers as:

[...] books of various genres that are specially created for learners of foreign languages. They may be simplified versions of existing works, original stories or books that are factual in nature. They are 'graded' in the sense that the syntax and lexis are controlled in order to make the content accessible to learners of the language (https://erfoundation.org,n.d.).

In his insightful article, Waring (2003) provided an exhaustive definition of graded readers when he maintained that:

One of the main functions of graded readers is to create a series of stepping stones for foreign language learners to eventually read unsimplified materials. It is fairly obvious that beginners cannot read unsimplified material enjoyably because of its difficulty, and in order to get the learners to the level where they are able to read unsimplified texts, they need to be stepped through materials of increasing levels of difficulty until they reach that point. By writing books at different difficulty levels (by simplifying the grammar, vocabulary and plot as well as adding illustrations to ensure adequate comprehension at that level) we can create these learning conditions (https://www.er-central.com).

It is clear from the given definitions that these readers were primarily designed to encourage ESL/ EFL students to read and help them absorb the language via the easily illustrated accessible instructional content/input in contrast to the original series which are characterized by the lengthy unsimplified content and require an advanced level of language proficiency. Accordingly, as many students proved themselves to be reluctant readers, who hardly ever read a book part of the curriculum, let alone for extensively, graded readers remain an effective solution to lower ability learners for reading cultivation habit and so for an incidental writing fluency. What is more, the graded levels are accompanied with comprehension, grammar, and vocabulary activities. These activities are of utmost importance to help learners sustain their grasp of the language and its meaning as well. It is true that graded readers were criticized for being over simplified and lacking authenticity, yet the latter should be revisited carefully. Widdowson (1998, as cited in Waring, 2003) argued that in the context of ESL/EFL we should talk about appropriate texts rather than authentic ones because learners for whom the text (content) was directed live outside the community (i.e., native speakers). This was stated clearly by Waring when he re-defines authenticity by stating that it is 'written for an intended 
audience'. Graded readers should not be mistaken for basal readers which are designed for L1. One could argue about the major difference if both types are intended for beginners. It should be taking into consideration, that L1 learners tackle the input from a cultural background and the already established mental dictionary where thousands of vocabulary items are inculcated, whereas L2 (ESL/EFL) learners learn not only the form, but the meaning as well since their repertoire is almost empty from the required headwords which often drives the learners to a misunderstanding of the meaning.

\subsection{The selective booklet}

The selective series on which this study is based are the Oxford Read and Discover nonfiction series published by Oxford University Press. There were many reasons for choosing the series. To mention, the proposed levels match the lower ability learners perfectly. Second, the activities of each chapter are located at the end of the booklet so that the drillings will not cause any constant interruptions to affect the reading fluency. Third, the booklets come with an audio book to help students in the reading process and benefit from the pronunciation as well. Fourth, there are well-illustrated headwords in the form of pictionary at the end of the books to help learners check the meaning. Fifth, each chapter is concise and illustrated thematically with picture stimulus to help students absorb the meaning. The booklet chosen consists of 750 headwords which matches the high elementary level according to the extensive reading scale (see appendix b). What is more, the booklets end with two writing activities to help students synthesize what they have learned through the reading process.

The choice of the booklet How to Stay Healthy was based on some principles for teaching extensive reading suggested by Bamford (2002). First, the reading material is easy and that was elicited from the students' impressions after the first reading. Second, a variety of materials were supplied at hand for students as extra-extensive reading. Third, students can choose what to read among the supplied series with the instructor's guidance, but not the already chosen one as part of the syllabus. For optimal engagement of students, I discussed with learners the reasons why I chose How to Stay Healthy to be the one we were going to read together in class. Among the principal reasons were the outdated textbook content on which they consented instantly. Moreover, students were astonished the moment I revealed that chapter three in the textbook will be covered (i.e., integrated skills) by the booklet as they never imagined the teacher could break the routine of relying heavily on the textbook. In addition to that, students were introduced to an overview of the research I intended to conduct so that I can help them in the writing fluency process. At that very moment, most students welcomed the idea enthusiastically to embark on reading the booklet which matches their major on top of the reasons mentioned.

\subsection{The role of the teacher and the student}

Having explained the objectives of using the booklet, I outlined the steps students should follow. First, students were given one week to finish reading the book, one week to comment on it on the discussion boards, one week to read it together in class, and the fourth week to take a writing quiz. Second, once they finish reading it, they resort to the online forum to write about their impressions of it. Their reflections should target the level of difficulty, illustrations, pictionary, note-taking, vocabulary items, new ideas, etc. The strategy implemented in here was to push students towards reading and reflect on the input acquired (i.e., vocabulary retention, grammatical structures, ideas, etc.) into a written form. At home, students can resort to dictionaries, online translation software, contact the teacher in private, or even pose any difficulty on the discussion boards to stimulate a graded writing fluency (indirectly) mirroring the items mentioned earlier. Afterwards, the in-class strategy begins in two-fold methods. First, I lead a discussion with students to check the degree of understanding of the input, the difficulties they faced, their favorite chapters, the sum of vocabulary items documented on their mini dictionaries (i.e., last part of the notebook), the new ideas they did not know before, etc. Once this process is done, there comes the second strategy where students are required to take turns reading chapters. Once a chapter is over, learners move directly to the activities. Before the session is over, students are asked again to take notes and go to the online forum to post their impressions about to what extent the class discussion was conducive to better understanding. Again, the strategy here was to push students to read, reflect, discuss, and write.

\section{Rational and purpose}

The main purpose of this mixed-method study is to argue about a linkage between graded readers as an independent variable and the writing graded fluency as a dependent variable. To fill the existing gap in the few studies that have been carried out in the field, this study aims at reinforcing research regarding the little inquiry which was directed towards this topic and its importance on the career of Moroccan EFL high school students which is characterized by low performance in the writing skill due to poor reading frequency.

\section{Research questions}

To examine the impact of graded readers on the writing performance (i.e., fluency) of the low-ability students, two principal research questions will be targeted: 
1. Do students report graded readers use in classroom to satisfy their learning needs?

2. To what extent do graded readers are conducive to improve their writing performance (fluency)?

\section{Methodology}

A mixed method study research design is used to measure the relationship between the students' satisfaction and writing fluency as dependent variables and the implementation of graded readers as an independent variable. In this study, classroom observations and online discussion forum on the Microsoft Teams platform, commissioned by the Moroccan Ministry of Education, is used to measure the 19 students' perceptions of graded readers. On the other hand, the students' quizzes on the writing skill as part of the formative assessment are used to quantitatively measure the impact of the graded readers on the writing ability. The participants in this study are the first Baccalaureate students of Al Imam Al Ghazali High school in Tetouan city who started learning English as a second foreign language just two years before the current academic year according to the Moroccan educational system. The choice of the sample ( $\left.1^{\text {st }} \mathrm{Bac}\right)$ was selective as students will be required to take the National Standardized Test in which they are supposed to write two pieces of writing. This experimental and exploratory study is strategically used to help students write and be prepared for the assigned final exam as their level of writing fluency is critical. The participants agreed on the terms of the research without any reference to their names or personal information. To measure the second variable (writing outcomes), the Rubric Calculator software is used to collect the data from the students' outcomes.

\section{Results}

\subsection{Students' perceptions}

At the outset of this academic year, students took a diagnostic test so that teachers could test their prior knowledge and language skills to make sure whether they were sufficient to embark on the English syllabus or to go through a remediation plan as decided by the ministerial circular every year. The results were unsatisfactory because of the Covid-19 quarantine and the schools' closure nationwide. In addition to that, the sample population did not receive any distance learning regarding the English language. I agreed with my students to cover some units in the textbook by means of the above-mentioned nonfiction book.

My initial observation was a bit surprising as students showed a great eagerness to experience a new method of dealing with the textbook. The online Microsoft Teams was used to measure the students' perceptions qualitatively towards the selective booklet to cover unit three under the title Health and Welfare. Most students who participated in that online forum expressed their total satisfaction after reading the booklet. It should be noted that at least some students did not participate due to the lack of ICT facilities at home because of their socio-economic circumstances. The students' impressions focused on the new method of approaching the textbook, difficulty of vocabulary choice, illustrations accompany each chapter, the quality of ideas (information), etc. Here are some examples of their perceptions. The names of students are removed to comply with research ethics. Also, the impressions were copied and pasted here without any modifications at all:

Student 1: I am* thankful to that non fictional book for the information he gave me and the knowledge i love how simple the sentences aren with deep meanings including the images that helps us to understand more and having the book a practice chapter is very useful so we can memorize the information without fear of losing it.

Student 2: I benefited from a lot information about a heathy food and somme exercises to protect my body and many information about digestion problems. Finally the book having more information interested.

Student 3: The story taught me many ways to stay healthy and what to eat and what not eat and activities to do but i felt sorry because my country didn't make this booklet it makes me feel sad because moroccans can't do any effort to reach their level.

Student 4: I benefited a lot from this book, as I got to know about the types of foods and how you can stay in good shape and a lot of things, it really is a great following.

Student 5: The book teaches us and advises us on how to take care of our mental and physical health, and gives us ideas to improve our day. It is a good way to learn and to learn new things about our body.

Student 6: I benefited from many things, including: the importance of healthy nutrition, the importance of exercising and its positive results. It is an ideal method to learn and heal our body, and to change our bad habits with playing sports.

Student 7: When I read it, I learned that a healthy diet, exercise and drinking water are very beneficial to the body and that abnormal foods harm the immune system.

It should be noted that other students' impressions on the online forum were not included for the sake of space, the identical observations or students did not participate due to the mentioned reasons. 


\subsection{Writing performance (fluency)}

To measure the second variable regarding the writing fluency, and for the purpose of this study, the key data were extracted from the students' (focused group) papers. The Rubric Calculator software (see appendix a) is used to grade the pieces of writing and calculate the final mark of each student including the percentage. On the other hand, the approach can be seen as a twostage process. First, students take the quiz including the writing which was part of the students' formative assessment and the instructor's strategy of syllabus intervention alternative. Then, the sample papers were graded using the primary trait rubric which was designed to evaluate only one aspect of language and be task-specific based (Lloyd-Jones, 1977). Although the rubric was originally designed to assess only one trait, the proposed software was customized to be a little analytical or multi traits to make the scoring process valid. The primary trait rubric is less known in contrast to the other types, yet it is useful in the context of EFL classes to measure focused aspects and grading students' writing performance. This section will focus on the scoring percentages of each trait with emphasis on word choice trait (vocabulary) as a key indicator of the writing fluency dependent variable to be consistent with the hypothesis of the interrelationship with the independent variable. The results are outlined in the following chart:

\begin{tabular}{|c|c|c|c|c|}
\hline Students & $\begin{array}{l}\text { Final mark } \\
--/ 10\end{array}$ & Percentage \% & $\begin{array}{l}\text { Word choice } \\
\text { weight } \\
---/ 5\end{array}$ & $\begin{array}{l}\text { Percentage } \\
\text { difference }\end{array}$ \\
\hline Student 1 & 9.75 & 98 & 5 & 51.28 \\
\hline Student 2 & 9.75 & 98 & 5 & 51.28 \\
\hline Student 3 & 9.75 & 98 & 5 & 51.28 \\
\hline Student 4 & 9 & 90 & 5 & 55.56 \\
\hline Student 5 & 6.85 & 69 & 3.75 & 54.74 \\
\hline Student 6 & 7.35 & 74 & 4 & 54.42 \\
\hline Students 7 & 7.15 & 72 & 3.75 & 52.45 \\
\hline Student 8 & 6.3 & 63 & 3 & 47.62 \\
\hline Student 9 & 7.15 & 72 & 3.75 & 52.45 \\
\hline Student 10 & 6 & 60 & 3 & 50 \\
\hline Student 11 & 5.6 & 56 & 3 & 53.57 \\
\hline Student 12 & 5.6 & 56 & 3 & 53.57 \\
\hline Student 13 & 5.4 & 54 & 3 & 55.56 \\
\hline Student 14 & 4.2 & 42 & 2 & 47.62 \\
\hline Student 15 & 3.8 & 38 & 2 & 52.63 \\
\hline Student 16 & 3.4 & 34 & 2 & 58.82 \\
\hline Student 17 & 3 & 30 & 2 & 66.67 \\
\hline Student 18 & 2.4 & 24 & 1 & 41.67 \\
\hline Student 19 & 2 & 20 & 1 & 50 \\
\hline Mean & 5.3 & -- & 3.17 & 52.69 \\
\hline
\end{tabular}

\section{Results and Discussion}

In the present study, two research questions were posed to assess the efficiency of graded readers on students' learning needs, and the extent to which these simplified booklets offer rich and easy absorbable vocabulary to help students in the writing process. As for the first question, students of the sampled level maintained very positive attitudes regarding the booklets used 
once they did the first reading. This was crystal clear from the online forum and in-class discussions about their impressions towards these readers or from the table above. By carefully examining the data, we discovered the following:

1. Students' major obstacles towards writing are the poor reading frequency and vocabulary limitation.

2. Students are discontented with the monotonous way writing is taught by teachers in class which does not match their low-ability performance.

3. The study is in harmony with Krashen's advocacy of comprehensible input before asking a student for output (production).

4. $31 \%$ scored below the average which is $2.5 / 5$ points.

5. $69 \%$ scored above the average in the word choice trait.

6. $52.69 \%$ is the mean of the word choice percentage of the scored marks in the writing skill.

7. 5.3 is the mean average of the scored marks. It was not remarkable, but the intention was to prioritize measuring the impact of the word choice trait rather than other traits namely, organization, sentence fluency and ideas.

8. Reading simplified graded readers have a strong impact on students' writing fluency.

9. Students should reflect on the input before writing and that was successful via the Microsoft Teams platform.

10. Media literacy is so important to stimulate students' reflections as pilot writing (guided writing) in an indirect way which allows them to synthesize what they read and demonstrate the corpus of vocabulary retention, grammatical structures and style of writing.

In brief, the results have demonstrated the adequacy of the method and better performance of students in the writing skill in contrast to what they revealed in the diagnostic test and previous formative assessment quizzes. However, this study has some limitations regarding the software used for the study. The software developed by the Smekenseducation.com does not provide the option of data analysis. Moreover, the only percentages provided are the ones related to the weight of each trait and the one related to the weight of the points out of the score. Furthermore, the rubric implemented emphasizes the word choice with 50\% of the scored weight at the expense of other traits. It should be noted that only four out of the six traits were scored with more focus on word choice to maintain the consistency of the study.

\section{Recommendations}

Depending on the results of the study from the primary collected data, I suggest the following recommendations to improve the students' writing performance and for further research:

- Graded readers series should be an integral part of the curriculum.

- Graded readers should not be viewed as supplementary materials.

- The Ministry of Education should grant teachers more freedom for syllabus intervention rather than sticking to the proposed writing topics in the outdated textbooks.

- The ministerial circular 142/2007 should be revised considering the teachers' suggestions and students' needs.

- $\quad$ To invest in training teachers to cater for students learning needs.

- Supplying graded readers collections considering the teachers' recommendations.

- Encouraging teachers to set up reading and writing clubs by providing incentives.

- $\quad$ The writing skill can be improved by media literacy, too.

- Encouraging the use of platforms like Microsoft Teams, online forums, Google docs, etc.

- Post stage activities should focus more on writing rather than being neglected at the expense of the pre- and whilestages by summarizing, commenting, synthesizing, evaluating, etc.

- Teachers should not ask students to write until they provide a simplified - 'comprehensible input' with clear instructions..

- Vocabulary should be contextualized so as students can decipher the meaning and so enrich their repertoires.

- To conduct more research on the impact of graded readers using the analytic rubric with equal weight to each trait rather than assigning more weight for the word choice for the sake of consistency and validity of the study.

- To conduct more research on the frequency of headwords in students' outcomes as a quantitative research.

- To shift from print readers to online ones, like the case of www.xreading.com which allow several benefits to teachers like online quizzes, audio, tracking reading progress of students, among a variety of collections provided there.

\section{Conclusion}

In summary, this study remains one of the humble attempts to measure the students' perceptions and satisfaction with a different approach to language skills (i.e., writing) and on the other hand, to measure the effects of graded readers on the students' writing fluency. Our students cannot be said to write until they are provided with graded simplified input. Language is learned primarily for communicative reasons, not only for classroom quizzes. By this, we mean that when teachers choose 
creative and effective method of teaching and scaffolding materials, our students should be able to speak and write fluently. By speaking, I mean to express their interests and perceptions freely since it was not the focus of our study here as a skill per se. Therefore, it is high time we rethink our teaching practices and materials we use in the classroom. It is true that graded readers have been criticized for the lack of authenticity, yet their benefits for the ESL/EFL students are of utmost importance as the study has demonstrated qualitatively and quantitatively in measuring the variables. Therefore, we suggest that teachers conduct more action research on the impact of graded readers using the analytic rubric with more focus on the frequency of headwords in students' outcomes as a quantitative research.

Funding: This research received no external funding.

Acknowledgments: Special thanks go to my wife and my daughter for their patience with me, and my supervisor Mrs. Mariam Bedraoui who encouraged me to write about my teaching experiences.

Conflicts of Interest: No conflict of interest.

\section{References}

[1] Cambridge Dictionary. (n.d.). GRADED READER. In Cambridge English Dictionary, Translations \& Thesaurus. Cambridge University Press. Retrieved June 18, 2021, from https://dictionary.cambridge.org/dictionary/english/graded-reader

[2] Cooper, C. R. (2020). Engagement with the selection, reading and discussion of online graded readers, a comparison between individual and group selected conditions. The Journal of International Languages and Cultures, Himeji Dokkyo University, 1, 21-38.

[3] Day, R. R., Bamford, J. (1998). Extensive reading in the second language classroom. RELC Journal, 29(2), 187-191. https://doi.org/10.1177/003368829802900211

[4] Day, Richard and Bamford, J. (2002). Top Ten Principles for Teaching Extensive Reading. Reading in a Foreign Language, 14(2), $136-141$.

[5] Johnson, M. (2014). Assessing the Impact of Graded Readers on Non-English Major's EFL Learning Motivation. In O'Rourke, B., Bermingham, \& Brennan, N. (Eds.), Opening New Lines of Communication in Applied Linguistics: Proceedings of the 46th BAAL Annual Meeting (Issue September). Scitsiugnil Press. http://baal.org.uk/proceedings_2013

[6] Krashen, S. (1993). The power of reading: Insights from the research. Englewood, CO: Libraries Unlimited.

[7] Smekens, K. (2011). Rubric Calculator - Smekens Education Solutions, Inc. Smekens Education Solutions, Inc. https://www.smekenseducation.com/rubric_calculator/

[8] Lloyd-Jones, R. (1977) Primary trait scoring. In Bridwell, L., Cooper, C. R., \& Odell, L. (eds.), Evaluating Writing: Describing, Measuring, Judging (67(9), pp. 33-66).The English Journal. https://doi.org/10.2307/815139

[9] The Extensive Reading Foundation. (n.d.). What Are Graded Readers? The Extensive Reading Foundation. Retrieved June 19, 2021, from https://erfoundation.org/wordpress/graded-readers/

[10] Waring, R. (2003). Writing a Graded Reader. Е режим доступу до статті http://www1. harenet. ne. jp/waring/papers/papers. html. 


\section{Appendix A}

\section{Rubric Calculator}

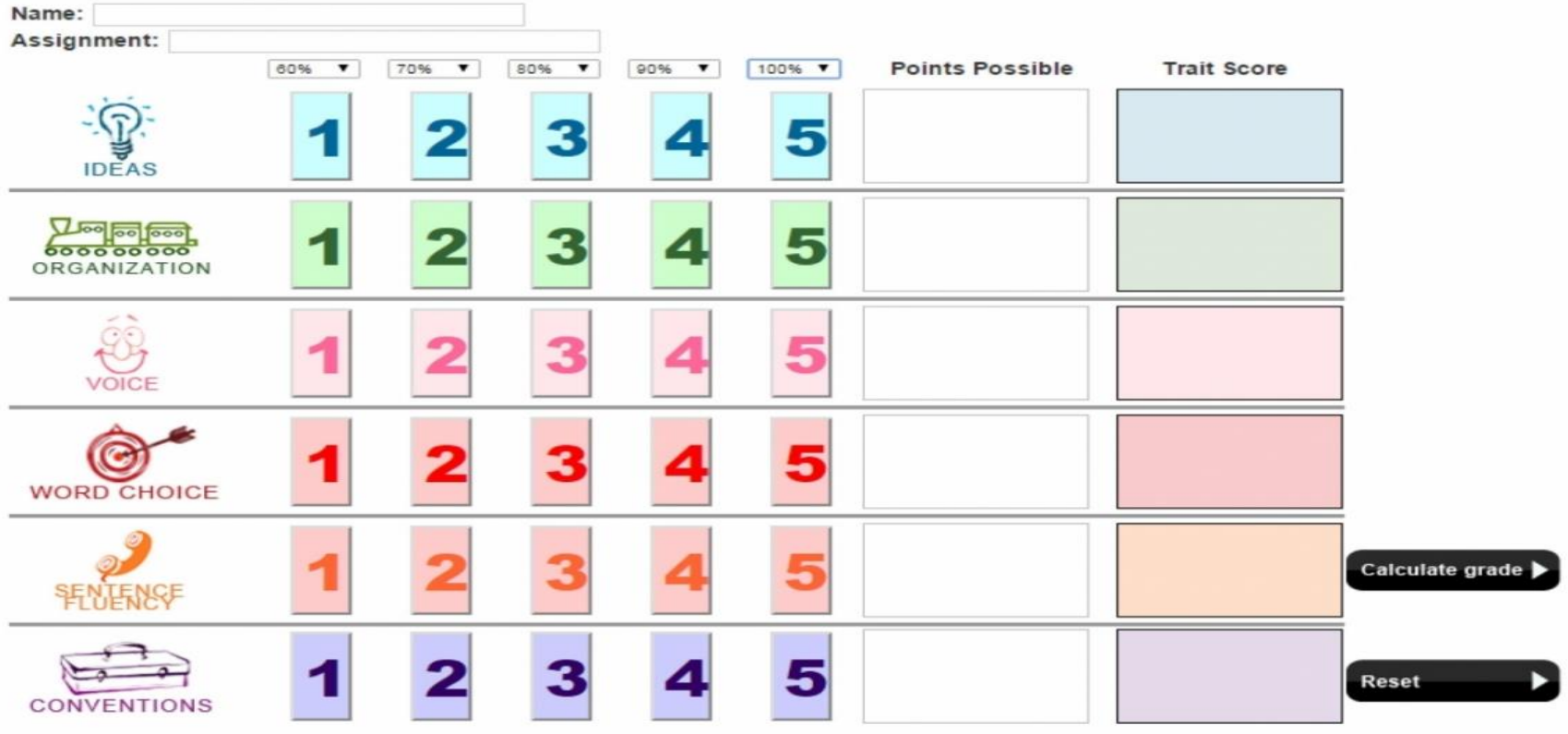

\section{Appendix B}

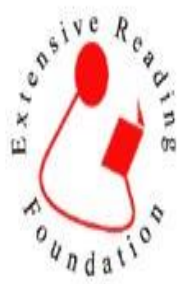

\section{The Extensive Reading Foundation Graded Reader Scale}

\begin{tabular}{|c|c|c|c|c|c|c|c|c|c|c|c|c|c|c|c|c|}
\hline & \multicolumn{4}{|c|}{ Beginner } & \multicolumn{3}{|c|}{ Elementary } & \multicolumn{3}{|c|}{ Intermediate } & \multicolumn{3}{|c|}{$\begin{array}{c}\text { Upper } \\
\text { Intermediate }\end{array}$} & \multicolumn{3}{|c|}{ Advanced } \\
\hline & Alphabet & Early & Mid & High & Early & Mid & High & Early & Mid & High & Early & Mid & High & Early & Mid & High \\
\hline $\begin{array}{l}\text { Headword } 1 \\
\text { count }\end{array}$ & 1.50 & $\begin{array}{l}51 \cdot \\
100\end{array}$ & $\begin{array}{l}101- \\
200\end{array}$ & $\begin{array}{l}201 . \\
300\end{array}$ & $\begin{array}{l}301- \\
400\end{array}$ & $\begin{array}{l}401- \\
600\end{array}$ & $\begin{array}{l}601- \\
800\end{array}$ & $\begin{array}{l}801 . \\
1000\end{array}$ & $\begin{array}{l}1001 . \\
1250\end{array}$ & $\begin{array}{l}1251 . \\
1500\end{array}$ & $\begin{array}{l}1501- \\
1800\end{array}$ & $\begin{array}{l}1801- \\
2100\end{array}$ & $\begin{array}{l}2101 . \\
2400\end{array}$ & $\begin{array}{l}2401 . \\
3000\end{array}$ & $\begin{array}{l}3001- \\
3600\end{array}$ & $\begin{array}{l}3601 . \\
4500\end{array}$ \\
\hline
\end{tabular}

